\title{
Healthy nutrition in Germany: a survey analysis of social causes, obesity and socioeconomic status
}

\author{
Sebastian Mader ${ }^{1, *}$ (10, Malte Rubach², Wolfram Schaecke ${ }^{2}$, Christine Röger $^{3}$, \\ Ina Feldhoffer ${ }^{3}$ and Eva-Magdalena Thalmeier ${ }^{3}$ \\ 'Institute of Sociology, University of Bern, 3012 Bern, Switzerland: ${ }^{2}$ Bavarian State Ministry for Nutrition, Agriculture, \\ and Forestry, 80539 Munich, Germany: ${ }^{3}$ Competence Centre of Nutrition (KErn) at the Bavarian State Research Center \\ for Agriculture, 85354 Freising, Germany
}

Submitted 22 January 2019: Final revision received 15 October 2019: Accepted 21 November 2019: First published online 27 April 2020

\begin{abstract}
Objective: The obesity pandemic is an increasing burden for society. Information on key drivers of the nutrition cycle of (a) social causation, (b) biological causation and (c) health selection is vital for effective policies targeted at the reduction of obesity prevalence. However, empirical causal knowledge on (a) the social predictors of diet quality, (b) its impact on corpulence and (c) the socioeconomic consequences of obesity is sparse. We overcome the limitations of previous research and acquire comprehensive causal insight into this cycle.

Design: Therefore, we analyse two German socio-epidemiological panel surveys exploiting their longitudinal panel structure utilising hybrid panel regression models.

Setting: General population of Germany.

Participants: German Health Interview and Examination Survey for Children and Adolescents (KiGGS, $n 17$ 640; age 0-24 years) and the German National Nutrition Monitoring (NEMONIT, $n$ 2610; age $15-82$ years).

Results: The results indicate that (a) interestingly only sex, education and age explain healthy diets; (b) increases in a newly developed Optimised Healthy Eating Index (O-HEI-NVSII) and in nuts intake reduce BMI, while growing overall energy intake, lemonade, beer and meat (products) intake drive corpulence; (c) in turn, developing obesity decreases socioeconomic status.

Conclusions: These results suggest that policies targeted at the reduction of obesity prevalence may be well advised to focus on boys and men, people with low education, the promotion of a healthy diet and nuts intake, and the limitation of lemonade, beer and meat (products) intake. Therefore, future research may focus on the replication of our findings utilising longer panels and experimental approaches.
\end{abstract}

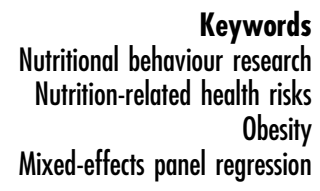

Not only in developed countries, the obesity pandemic and its related secondary diseases are an increasing burden for social care systems, economic productivity and individual quality of life ${ }^{(1)}$. People suffering from overweight and obesity have a higher risk of dying prematurely ${ }^{(2)}$, developing cardiometabolic multimorbidity ${ }^{(3)}$, Alzheimer's disease ${ }^{(4)}$ and pancreatic and breast cancer ${ }^{(5,6)}$. With its unrelieved growth of about $1 \%$ per year ${ }^{(7)}$, the obesity pandemic puts a serious and increasing burden of direct and indirect costs on social security systems as well as tangible and intangible costs on individuals ${ }^{(1,8)}$. In contrast, a balanced diet is expected to reduce obesity-induced morbidities and allcause mortality ${ }^{(9)}$.
Various theoretical approaches have been used to explain diet quality and its health outcomes ${ }^{(10,11)}$. The two most prominent hypotheses derived from them are the 'social causation hypothesis' and the 'health selection hypothesis'. While the former theorises that manifold socioeconomic, sociodemographic and sociocultural factors drive health outcomes of diets like corpulence, the health selection hypothesis inter alia assumes that nutritional health outcomes predict social outcomes. So far, evidence for the relative empirical validity of these seemingly opposing hypotheses is inconclusive and fragmented ${ }^{(12)}$. Moreover, the social causation hypothesis often implicitly assumes a direct deterministic link between diet quality 


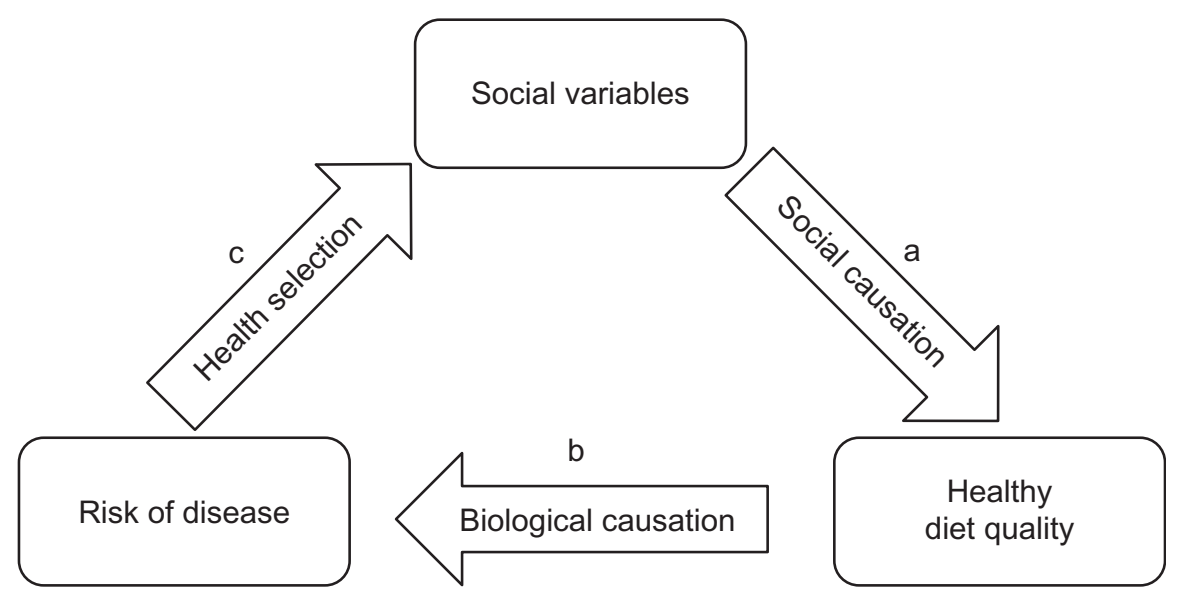

Fig. 1 The nutrition cycle

and corpulence. For that reason, most studies testing the social causation hypothesis directly regress nutritional health outcomes on social factors, for example, BMI on socioeconomic status (SES). However, for the identification of the causal nutritional socio-epidemiological mechanisms, this approach oversimplifies, as it disregards the biological causation path regressing health outcomes on diets. Only the inclusion of this path guarantees a comprehensive insight in the causal relationships in a so-called 'nutrition cycle' (see Fig. 1), where social factors are hypothesised to predict diet quality (social causation (a)); nutrition impacts corpulence (biological causation (b)); and corpulence affects social outcomes (health selection (c)). This causal spiral in time can be viewed as both intragenerational, explaining intrapersonal life courses, and intergenerational, referring to the (epi)genetic and social inheritance of health chances.

Social determinants of diet quality (a) are hypothesised to be manifold ${ }^{(10,13,14)}$. They range from individual and contextual socioeconomic factors (e.g. SES, employment status, healthy food availability) to sociodemographic factors (e.g. sex, age, migration background) to sociocultural factors (e.g. sex, migration background and regional diet imprints of origin) and other factors (e.g. physical activity and psychological problems) ${ }^{(13)}$. In this vein, social factors affecting nutrition outcomes could also be subsumed to categories such as affordability, availability and accessibility of foods. This so-called 'triple-A' model ${ }^{(14)}$ is a synthesis of the principles of behavioural economics and humanecological setting approaches ${ }^{(15)}$ to model the dimensions of individual dietary decisions: Affordability comprises both direct costs and opportunity costs of foods. Availability refers to the availability of foods, as well as to the surrounding opportunity structure, and thus to the contextual features of a social space. Finally, accessibility encompasses internalised cultural knowledge and the associated scripts. More specifically, accessibility refers to characteristics like educational background or attainment, as well as to normative attitudes and associated characteristics as regards the socioeconomic and sociocultural attributes of foods ${ }^{(16)}$.

Generally, information on key drivers of the 'nutrition cycle' is vital for effective explicit and implicit behavioural political interventions targeted at the reduction of obesity prevalence and health promotion ${ }^{(17,18)}$. Yet, causal empirical evidence on the 'nutrition cycle' is sparse. So far, there are only six studies that analyse population-based socioepidemiological panel surveys with measurements of all relevant variables at all points in time for either $(a)^{(19,20)}$, or $(b)^{(21-23)}$, or (c) ${ }^{(24)}$ and applying panel regression models (see Table 1).

All six presented studies advantageously use panel data applying multiple panel regression models. Nonetheless and besides individual weaknesses, these six studies have some limitations in common: first, five of the studies are based on data from the United States ${ }^{(19,20,22-24)}$; only one study stems from another country (Belgium) ${ }^{(21)}$. Hence, the state of research on the nutrition cycle is geographically restricted to two countries. Second, none of the six studies includes time dummies as confounders that would account for overall time trends (i.e. overall time-varying unobserved heterogeneity). Third, none of the six studies covers the full age range. Fourth and finally, all of the six studies are limited to the analysis of only one of the analytical paths of the nutrition cycle ((a) or (b) or (c)).

\section{Data and methods}

Hence, this study aims at overcoming these limitations and acquires a comprehensive insight into the whole nutrition cycle by analysing two German socio-epidemiological survey panel datasets utilising hybrid generalised linear mixed panel regression models: two waves of the German Health Interview and Examination Survey for Children and Adolescents (KiGGS) aged 0-24years ( $n$ 17640) between 2003 and 2012, and five waves of the German National Nutrition Monitoring (NEMONIT) ${ }^{(25)}$ panel study 


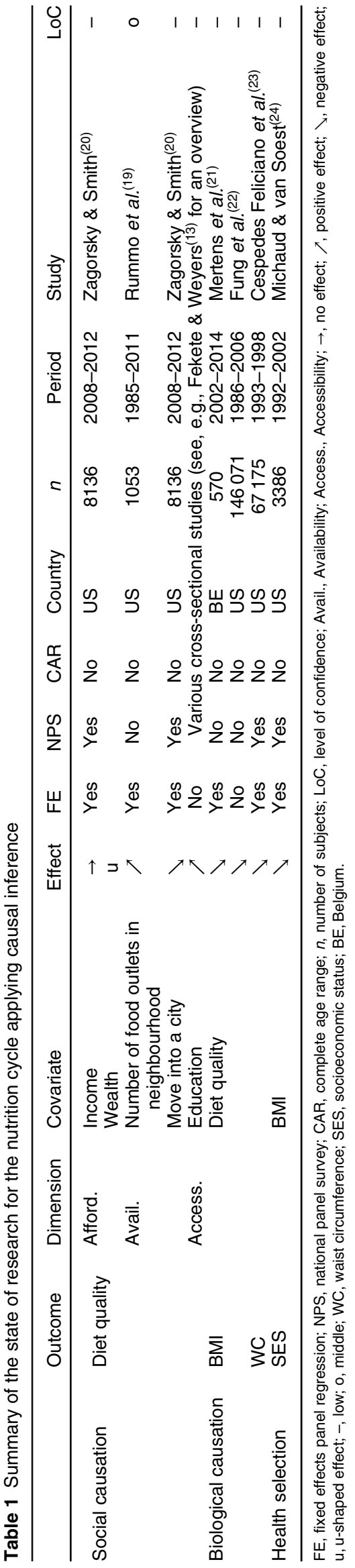

for 15- to 82-year-olds ( $n$ 2610) surveyed between 2005 and 2013. Both KiGGS and NEMONIT datasets consist of random samples of the German population and together cover an age range from 0 to 82 years as well as an observation period of about a decade between 2003 and 2013. KiGGS 0 received ethical approval from the German Federal Data Protection Office and the Ethics Committee of Charité University Medicine ${ }^{(26)}$. KiGGS 1 received ethical approval from the Hanover Medical School's ethics committee and the Federal Commissioner for Data Protection and Freedom of Information(27). NEMONIT received ethical approval from the German Federal Data Protection Office ${ }^{(28)}$. Written informed consent was obtained in detail from the respondents in all of the three studies ${ }^{(26-28)}$.The central characteristics of KiGGS and NEMONIT panels, also with regard to the measurement of central characteristics for this study, are summarised in Table 2. The online Supplemental Tables S1, S2, S3 and S4 in the Supplementary Material show descriptive statistics and measurement descriptions of all variables included in the analyses.

\section{Affordability and availability contexts}

The comparatively large number of cases and sample points in the KiGGS panel allows a relatively fine-grained spatial segmentation and, therefore, the analysis of effects of affordability and availability contexts on diet quality: County- and state-level data on average disposable income per capita (p.c.) from the Regional Database Germany of the statistical offices of the confederation and the federal states were merged with the KiGGS data. County-level data on the number of retail firms and firms in the food service industry p.c., and on the factory area of trade and industry p.c., were also added from the Regional Database Germany. These three context indicators are used to approximate the variety of healthy food supply, as purchasing power is an important location factor for food retailers. Moreover, the number of firms and sales area are associated with product variety ${ }^{(29)}$.

\section{Food intake}

As the concept of 'healthy nutrition' is widely disputed and operationalised in manifold ways, in this study we provide a diverse selection of indicators of a healthy diet. The two datasets differ in the measurement of food intake: In the KiGGS panel, the usual intake of only five food groups (fruits, vegetables, juices, sweetened soft drinks and sweets) is measured with a food frequency questionnaire (FFQ) retrospectively for the last 4 weeks $^{(30)}$ in both available waves. However, there is no fundamental restriction for the calculation of indicators of intake quality, for example, following the concept of the Healthy Nutrition Score for Kids and Youth (HuSKY; see Kleiser et al. ${ }^{(31)}$ for details). HuSKY is a Healthy Eating Index (HEI) specially designed for children and adolescents in accordance with 
Table 2 Comparison of central data characteristics

\begin{tabular}{|c|c|c|}
\hline & KiGGS & NEMONIT \\
\hline Cases & $N 29632, n 17640$ & $N 13050, n 2610$ \\
\hline Waves & 2 (KiGGS $0+$ KiGGS 1$)$ & 5 (NVSII $+4 \times$ NEMONIT) \\
\hline Time span & $2003-12$ & $2005-13$ \\
\hline Age range & $0-24$ & $15-82$ \\
\hline Spatial segmentation & Counties, states & Regions (east, west, north, south) \\
\hline Food intake & $\begin{array}{l}\text { FFQ of usual intake of five } \\
\text { food groups in the last } \\
4 \text { weeks }\end{array}$ & $\begin{array}{l}\text { Two 24-h recalls of acute intake of } \\
\text { seventeen food groups }\end{array}$ \\
\hline Anthropometry & $\begin{array}{l}\text { Not available for panel } \\
\text { analysis }\end{array}$ & $\mathrm{BMI}$ \\
\hline $\begin{array}{l}\text { Socioeconomic, } \\
\text { sociodemographic } \\
\text { and sociocultural } \\
\text { variables }\end{array}$ & Extensive & Extensive \\
\hline
\end{tabular}

KiGGS, German Health Interview and Examination Survey for Children and Adolescents; NEMONIT, German National Nutrition Monitoring; NVSII, National Nutrition Survey II; ' $n$ ' refers to the number of individuals, and ' $N$ ' to the number of observations (' $n$ ' times the number of years ' $T$ '); data sources: KiGGS panel from Robert Koch-Institute; NEMONIT from Max Rubner-Institute ${ }^{(25)}$.

the food group-specific intake recommendations of the Optimised Mixed Diet ${ }^{(32,33)}$. In addition, the Healthy Food Diversity (HFD) Index ${ }^{(34)}$ can be calculated from the relative recommended intake ratio of amply recommended (here fruits, vegetables and juices) to tolerated (i.e. foods with high energy density (ED) and low nutrient content - here sweetened soft drinks and sweets) food groups according to the Optimised Mixed Diet.

By contrast, in the NEMONIT panel, the acute intake of seventeen food groups of the previous day is surveyed via two 24-h recall telephone interviews ${ }^{(35)}$. As the acute food intake varies by weekday and season, all models using NEMONIT diet data control for these variables. The comprehensive diet survey in NEMONIT enables the calculation of various indicators of intake quality. First, an HEI in accordance with the dietary recommendations of ten food groups of the German Nutrition Society (DGE) ${ }^{(36)}$ could be computed as suggested in Gose et al. (HEI-NVSII, 2016) ${ }^{(28)}$. HEI-NVSII, like other conventional Healthy Eating Indexes, describes intake compliance with dietary guidelines usually on a ratio scale from $0=$ 'no compliance' to $100=$ 'full compliance' based on food group-specific recommendations in absolute grams per day. The range of the original HEI-NVSII is $0-110$, as the maximum score for fruit and vegetable intake is 15 each instead of 10 for the other food groups included ${ }^{(28)}$. However, this range can be normalised to $0-100$. Yet, recommendations in absolute terms depend on, for example, sex, age, body weight and level of physical activity. This introduces substantial assumptions on individual characteristics that could impose risks of producing a methodological artefact. Consequently, we suggest an Optimised HEI-NVSII (O-HEI-NVSII). This is the additive index of compliance with the dietary guidelines of ten food groups based on the sex-specific relative shares of the whole intake (in g/d) on a scale from 0 to 100 taken from Gedrich and Karg ${ }^{(37)}$. Thus, O-HEI-NVSII supposedly has the comparative advantage that relative recommendations are only to a relatively small extent prone to individual characteristics. The single prerequisite to compute O-HEI-NVSII is information on the whole daily intake in grams, which is met by NEMONIT, but not by the KiGGS panel. Moreover, HEI are applied to recommendations of macronutrient intake (HEI-MAC) ${ }^{(38)}$ based on relative shares and to guidelines for energy intake (HEI-EN) ${ }^{(39)}$. The HFD index is calculated following Drescher et al ${ }^{(34)}$. Lastly, the average ED in $\mathrm{kcal} / \mathrm{g}$ is calculated. Owing to the recent discussion about the concept of ED, we compute both the ED of the energetic food intake excluding non-energetic beverages and drinking water (ED1) and the ED of the non-beverage food intake excluding all beverages (ED2) ${ }^{(40,41)}$.

\section{Antbropometry}

The BMI as a measure of corpulence is only available in the NEMONIT panel. Therefore, it is possible to analyse the whole nutrition cycle with NEMONIT, while the social causation path can be analysed for KiGGS. In NEMONIT, the $\mathrm{BMI}$ is surveyed as a self-report of body weight and height, while in the NVSII (the first wave of NEMONIT), objective measures were taken, too. However, the self-reported and the objective BMI are correlated very highly (Spearman's $r_{s}=0.98$; Pearson's $r_{p}=0.99 ; n$ 2551), and the distributions are virtually identical (objective measure: mean 25.9 , SD $4 \cdot 8$, minimum $15 \cdot 8$, maximum $57 \cdot 8$; self-report: mean $25 \cdot 4$, SD $4 \cdot 5$, minimum $16 \cdot 0$, maximum $56 \cdot 2 ; n$ 2551). The same applies to the underlying measurements of body height and weight. This indicates a high external validity of selfreported BMI.

\section{Social variables}

Finally, socioeconomic, sociodemographic and sociocultural variables are surveyed in detail in KiGGS (educational background, parental job position, parental employment 
status, household size, sex, age and migration background) as well as in NEMONIT (educational attainment, job position, employment status, partnership status, household size, sex and age). All the variables included in the reported models of Tables 3-7 are described in online Supplemental Tables S1-S4 of the Supplementary Information. As the online Supplemental Tables S1 and S3 reveal, diets are not a stable exposition, but underlie considerable variation within subjects over time. The same applies for all other time-varying characteristics shown in online Supplemental Tables S1-S4.

All in all, the available KiGGS panel only enables the analysis of the social causation path, while all three paths of the nutrition cycle can be analysed with the available NEMONIT panel data. It should be noted that a conceivable alternative for NEMONIT could be the German Health Interview and Examination Survey for Adults (DEGS). However, NEMONIT has more available observation waves than DEGS, and in DEGS, food intake is not measured identically in all waves.

\section{Analytics}

Concerning the analytics, fixed effects (FE) panel regression exploits the longitudinal data structure of panels as it only takes variations within the individuals' life courses into account. Thus, the FE estimator is unbiased in the presence of cross-sectional unobserved heterogeneity affecting both the observed covariates and the outcome ${ }^{(42,43)}$. If the strict exogeneity assumption holds, the FE regression adequately estimates unbiased causal effects of the covariates on the outcome ${ }^{(44)}$. For instance, this enables the identification of the effect of ageing on dietary quality while controlling for birth cohort categories or whether an increase in dietary quality induces a decrease in BMI. However, it is still common practice in most of the epidemiological prospective cohort studies not to regress changes in the outcome on changes in the covariates. This practice implicitly assumes that diets are a timeinvariant exposition and remain stable over the individuals' life courses ${ }^{(21)}$. This assumption is not empirically valid, as the KiGGS and NEMONIT data as well as Mertens et $a l^{(17)}$ demonstrate.

Nevertheless, standard FE models can only estimate the effects for time-varying variables and do not allow the inclusion of time-invariant characteristics. The generalised linear mixed panel regression model (so-called hybrid model $)^{(45,46)}$ simultaneously estimates fixed, between and random effects. Thus, the hybrid model enables the inclusion of both time-varying (e.g. income) and time-invariant (e.g. migration background) variables in the same model. As it is true for the FE model, the hybrid model's FE estimates are unbiased, if the strict exogeneity assumption holds ${ }^{(44)}$. Given the outlined advantages of the hybrid model, it is applied throughout the analyses. The specification of the hybrid model and an overview of the sensitivity analyses performed for all the reported regression results can be found in the supplement.

\section{Results}

Overall, the results indicate that sex, education and age explain diet quality. Increases in the newly developed O-HEI-NVSII and in nuts intake reduce BMI, while growing overall energy intake, lemonade, beer, meat and meat product intakes drive corpulence. In turn, developing obesity decreases SES. The results of the analyses for social causation, biological causation and health selection path are explained in more detail below.

\section{Social causation}

The social causation path could be analysed for both the KiGGS and NEMONIT panels. As an introspection of Tables 3 and 4 consistently reveals, girls and women generally eat healthier (as measured by HuSKY and HEI) and have more diverse diets (as measured by the HFD Index) than boys and men. Moreover, children and adolescents with parents of high educational attainment have healthier and more diverse diets than peers with low educational background (see Table 3). The same applies to the educational attainment of adults. Furthermore, the dietary diversity of adults decreases with increasing age controlling for 2-year birth cohort categories (see Table 4).

In addition, in KiGGS, we observe an interaction effect between individual equivalence income and the average disposable county-level income on intake. With increasing individual income and high average disposable income in the county of residence (20000-38000 $€$ per year), the intake of tolerated foods rises, while there is no relation for middle county income $(15000-<20000 €$ per year) and a negative relation for low county income (10 000$<15000 €$ per year) (see Fig. 2). Interestingly, this interaction effect is not statistically significant for the intake of amply recommended food groups (see Fig. 3).

For adults in NEMONIT, we found no effect of individual equivalence income on intake. Moreover, adults living in eastern Germany have higher HFD Index values than people living in the rest of Germany, indicating higher food diversity in eastern Germany (see Table 4).

Neither in KiGGS nor in NEMONIT, the triple-A model can explain the ED of diets as measured by ED1, including energetic beverages (see model 7 of Table 3 and model 5 of Table 4). As an introspection of model 8 of Table 3 and model 6 of Table 4 reveals, girls and women have a lower average ED when computed excluding all beverages (ED2).

All other variables included in the models do not substantially and consistently relate to healthy and diverse nutrition comparing the models using different indicators of diet quality (see Tables 3 and 4). 


\section{Nes Public Health Nutrition}

Table 3 KiGGS: generalised mixed-effects regressions: intake quality†

\begin{tabular}{|c|c|c|c|c|c|c|c|c|c|}
\hline \multirow[b]{2}{*}{ Model } & & 1 & 2 & 3 & 4 & \multirow[b]{2}{*}{5} & \multirow[b]{2}{*}{6} & \multirow[b]{2}{*}{7} & \multirow[b]{2}{*}{8} \\
\hline & & Amp.Rec. & Tolerated & Amp. Rec. & Tolerated & & & & \\
\hline \multicolumn{2}{|l|}{ Dependent variable } & \multicolumn{2}{|c|}{$\mathrm{g} / \mathrm{d}$} & \multicolumn{2}{|c|}{$\mathrm{kcal} / \mathrm{d}$} & HUSKY & HFD Index & ED1 & ED2 \\
\hline \multirow[t]{2}{*}{ Equivalence income (unit $1000 €$ ) } & $(\mathrm{F})$ & $-12 \cdot 01^{\star \star \star}$ & $-7 \cdot 33^{\star \star \star}$ & $-5 \cdot 81^{\star \star \star}$ & $-14 \cdot 42^{\star \star \star}$ & -0.03 & 0.15 & -0.00 & -0.00 \\
\hline & SE & 3.06 & 1.83 & 1.43 & 3.09 & 0.14 & 0.15 & 0.00 & 0.00 \\
\hline \multirow[t]{2}{*}{ County-level disposable income p.c. } & $(F)$ & $-109 \cdot 90^{\star \star *}$ & $-66 \cdot 12^{\star \star *}$ & $-50 \cdot 99^{* * *}$ & $-113 \cdot 68^{\star * \star}$ & $-2 \cdot 22$ & -0.40 & -0.01 & -0.02 \\
\hline & SE & $30 \cdot 30$ & 18.82 & $14 \cdot 21$ & 27.94 & 1.40 & 1.49 & 0.02 & 0.03 \\
\hline \multirow[t]{2}{*}{ State-level disposable income p.c. } & $(\mathrm{F})$ & $-117 \cdot 01^{\text {***}}$ & $-21 \cdot 86$ & $-54 \cdot 21^{\star \star \star}$ & $-40.33^{+}$ & -0.44 & -1.66 & 0.02 & 0.02 \\
\hline & SE & $32 \cdot 31$ & $20 \cdot 48$ & 15.98 & $20 \cdot 89$ & 1.40 & 1.47 & 0.02 & 0.03 \\
\hline \multirow{2}{*}{$\begin{array}{l}\text { Interaction: Equivalence income and county level } \\
\text { disposable income }\end{array}$} & $(F)$ & $57 \cdot 74^{\star \star \star}$ & $40 \cdot 65^{\star \star \star}$ & $26 \cdot 79^{\star \star \star}$ & $73.69^{\star \star \star}$ & 0.53 & -0.67 & 0.01 & 0.02 \\
\hline & SE & 14.01 & 8.04 & 6.50 & $12 \cdot 80$ & 0.69 & 0.70 & 0.01 & 0.01 \\
\hline \multirow[t]{2}{*}{ Eastern Germany } & $(\mathrm{R})$ & $30 \cdot 17$ & $20 \cdot 18$ & $28 \cdot 87^{\star \star}$ & $10 \cdot 47$ & $1 \cdot 17$ & 0.21 & 0.00 & 0.00 \\
\hline & SE & $22 \cdot 01$ & $15 \cdot 27$ & 10.41 & $16 \cdot 87$ & 0.82 & 1.08 & 0.01 & 0.02 \\
\hline \multirow[t]{2}{*}{ Large city } & $(\mathrm{F})$ & $53 \cdot 35$ & -8.60 & 24.49 & $30 \cdot 08$ & 2.09 & 1.76 & -0.03 & -0.06 \\
\hline & SE & 62.93 & $26 \cdot 37$ & $30 \cdot 77$ & $38 \cdot 13$ & $2 \cdot 76$ & $2 \cdot 62$ & 0.04 & 0.05 \\
\hline \multirow[t]{2}{*}{ Number of firms p.c. } & $(F)$ & $61 \cdot 77$ & -7.86 & 34.71 & 24.41 & 3.57 & $4 \cdot 80^{\star}$ & -0.01 & 0.04 \\
\hline & SE & 48.97 & 29.48 & 23.25 & $44 \cdot 31$ & 2.35 & 2.45 & 0.03 & 0.05 \\
\hline \multirow[t]{2}{*}{ Interaction: large city and number of firms p.c. } & $(\mathrm{F})$ & $-65 \cdot 76$ & $69 \cdot 24^{+}$ & -27.59 & $13 \cdot 19$ & $-6 \cdot 75^{+}$ & $-9 \cdot 32^{\star \star}$ & 0.03 & 0.03 \\
\hline & SE & $72 \cdot 68$ & 35.59 & 34.93 & 58.65 & 3.46 & 3.39 & 0.05 & 0.07 \\
\hline \multirow[t]{2}{*}{ Firm area $10-<20 \mathrm{ha} / 10000 \mathrm{c}$} & $(\mathrm{F})$ & -3.83 & 8.68 & -2.91 & 18.46 & 0.81 & -0.76 & 0.01 & 0.00 \\
\hline & SE & 24.99 & $15 \cdot 10$ & 11.99 & 18.96 & 1.09 & $1 \cdot 24$ & 0.02 & 0.02 \\
\hline \multirow[t]{2}{*}{ Firm area $20-<80 \mathrm{ha} / 10000 \mathrm{c}$} & $(\mathrm{F})$ & -18.77 & $12 \cdot 64$ & $-6 \cdot 20$ & $36 \cdot 98$ & 0.21 & -0.75 & 0.01 & -0.00 \\
\hline & SE & 41.95 & $27 \cdot 80$ & 19.90 & 35.54 & 1.91 & $2 \cdot 17$ & 0.03 & 0.04 \\
\hline \multirow[t]{2}{*}{ Mother: Education } & (B) & $21 \cdot 13^{\star \star \star}$ & $-29 \cdot 66^{\star \star \star}$ & $8.39^{* *}$ & $-14 \cdot 51^{\star *}$ & $1 \cdot 10^{* * *}$ & $2 \cdot 23^{\star \star *}$ & 0.00 & 0.01 \\
\hline & SE & $5 \cdot 81$ & $4 \cdot 16$ & 2.79 & 4.59 & 0.21 & 0.28 & 0.00 & 0.01 \\
\hline \multirow[t]{2}{*}{ Father: Education } & (B) & $21 \cdot 28^{\star \star \star}$ & $-20 \cdot 70^{\star \star \star}$ & $9 \cdot 46^{\star \star \star}$ & $-6 \cdot 10$ & $0.96^{* \star *}$ & $1.77^{\star \star \star}$ & -0.00 & 0.01 \\
\hline & SE & 5.57 & 3.98 & $2 \cdot 66$ & 4.63 & 0.20 & 0.27 & 0.00 & 0.01 \\
\hline \multirow[t]{2}{*}{ Parental job position } & $(\mathrm{F})$ & $-10 \cdot 65$ & $-2 \cdot 78$ & -4.87 & -3.59 & -0.32 & -0.05 & 0.00 & 0.01 \\
\hline & SE & 7.44 & 4.58 & 3.50 & 6.04 & 0.33 & 0.37 & 0.00 & 0.01 \\
\hline \multirow[t]{2}{*}{ Mother: Part-time employed } & $(\mathrm{F})$ & $-5 \cdot 18$ & $-9 \cdot 44$ & $-2 \cdot 00$ & $-9 \cdot 60$ & -0.40 & 0.48 & 0.00 & -0.00 \\
\hline & SE & $17 \cdot 82$ & $10 \cdot 27$ & 8.40 & 13.58 & 0.79 & 0.86 & 0.01 & 0.02 \\
\hline Mother: Full-time employed & $(\mathrm{F})$ & $-7 \cdot 83$ & $-9 \cdot 12$ & $-1 \cdot 21$ & $-16 \cdot 12$ & 0.15 & 0.61 & -0.01 & -0.03 \\
\hline & SE & 27.99 & $17 \cdot 82$ & $13 \cdot 13$ & 25.46 & 1.23 & 1.38 & 0.02 & 0.03 \\
\hline Father: Part-time employed & $(\mathrm{F})$ & $5 \cdot 20$ & -10.78 & 6.67 & $19 \cdot 72$ & 1.94 & 2.45 & 0.02 & -0.05 \\
\hline & SE & 54.66 & 36.54 & $26 \cdot 51$ & $39 \cdot 18$ & $2 \cdot 37$ & $2 \cdot 64$ & 0.03 & 0.05 \\
\hline Father: Full-time employed & $(\mathrm{F})$ & 23.66 & $-54 \cdot 11^{*}$ & $15 \cdot 36$ & $-55 \cdot 16^{\star}$ & $2 \cdot 74$ & $3.53^{+}$ & -0.01 & $-0.07^{+}$ \\
\hline & SE & 35.48 & $23 \cdot 82$ & $16 \cdot 61$ & $27 \cdot 45$ & 1.68 & 1.87 & 0.02 & 0.04 \\
\hline Household size & $(\mathrm{F})$ & $-14 \cdot 60$ & 5.46 & -5.58 & $20 \cdot 40$ & -1.00 & $-1 \cdot 37^{+}$ & $0.02^{*}$ & 0.02 \\
\hline & SE & 14.87 & $9 \cdot 70$ & 7.09 & $13 \cdot 15$ & 0.71 & 0.75 & 0.01 & 0.02 \\
\hline Female & (R) & $13 \cdot 87$ & $-67 \cdot 81^{\star \star \star}$ & $7 \cdot 20^{+}$ & $-66 \cdot 21^{\star \star \star}$ & $3.64^{\star \star \star}$ & $4 \cdot 66^{\star \star \star}$ & -0.00 & $-0.08^{\star \star \star}$ \\
\hline & SE & $9 \cdot 11$ & 6.56 & 4.35 & 7.40 & 0.33 & 0.44 & 0.01 & 0.01 \\
\hline Age & $(\mathrm{F})$ & $19 \cdot 68$ & $42 \cdot 21^{*}$ & $8 \cdot 17$ & 34.01 & $2 \cdot 34^{+}$ & 0.38 & -0.01 & 0.03 \\
\hline & SE & $33 \cdot 12$ & $18 \cdot 77$ & $15 \cdot 59$ & $26 \cdot 13$ & 1.36 & 1.54 & 0.02 & 0.03 \\
\hline Age squared & $(\mathrm{F})$ & $-3 \cdot 83^{\star \star \star}$ & $-2 \cdot 46^{\star \star \star}$ & $-1 \cdot 75^{\star \star \star}$ & $-4 \cdot 17^{\star \star \star}$ & $-0.03^{*}$ & $0.08^{\star \star *}$ & $-0.00^{\star \star \star}$ & -0.00 \\
\hline & SE & 0.24 & 0.15 & 0.12 & 0.20 & 0.01 & 0.01 & 0.00 & 0.00 \\
\hline
\end{tabular}




\section{Biological causation}

The analysis of the biological causation path (only possible for NEMONIT) reveals that increases in O-HEI-NVSII and nuts intake reduce BMI, while growing overall energy intake, lemonade, beer, meat and meat product intakes increase BMI (see Tables 5 and 6).

As models 1.1 and 1.2 of Table 5 show, a healthier diet decreases BMI. This indicates that O-HEI-NVSII has some predictive validity. Nevertheless, the effect is very small. Per ten index points healthier diet, BMI decreases by $0 \cdot 10$. However, this is not the case for increases in intake diversity, as the HFD Index is not related to BMI in NEMONIT. Most surprisingly at first glance, growing ED yields BMI losses net of overall energy intake, which has a relatively small positive effect on BMI. The effect of $\mathrm{ED}$, including non-beverage food groups and energetic beverages, is around twice as large as the effect of ED, including non-beverage food groups only.

Models 2 and 3 of Table 5 reveal that independent from all other macronutrients, only increases in alcohol consumption increase BMI substantially. As the food grouplevel analyses of the models 8 and 9 of Table 6 expose, this effect is only attributable to increases in beer consumption controlling for (sparkling) wine, spirits and all other food group-specific intake.

Further detailed influences on BMI can be obtained from the food group-specific models in Table 6: being very energy-dense foods, nuts, in combination with their unique composition of a variety of high-quality nutrients, have various health-promoting effects ${ }^{(47)}$. This study confirms clinical trials that suggest that an increase in nuts consumption yields a decrease in visceral adiposity ${ }^{(47)}$. Moreover, rising intakes of lemonade, meat and meat products ceteris paribus drive corpulence, with the effect of lemonade being six times as high as the effects of meat or meat products each. Changes in the intake of other food groups do not affect BMI as it also applies to the categorisation of food groups (see models 4 and 5 of Table 5). Finally, the models in Tables 5 and 6 also show that women have a lower BMI compared to men and that age does not drive corpulence in the NEMONIT panel.

\section{Health selection}

In turn, the analysis of the health selection path (only for NEMONIT) reveals that developing obesity leads to losses in SES (see Table 7). Specifically, developing obesity decreases adults' job position as well as the associated prestige (model 2). However, developing obesity does not affect equivalence income (model 1). Reporting a good health condition is associated with a higher job position, and women earn less and have lower job positions.

\section{Discussion and conclusion}

For the first time, this study acquires a comprehensive causal insight into the nutrition cycle by identifying the 
Table 4 German National Nutrition Monitoring (NEMONIT): generalised mixed-effects regressions: intake quality†

\begin{tabular}{|c|c|c|c|c|c|c|c|}
\hline Model & & 1 & 2 & 3 & 4 & 5 & 6 \\
\hline Dependent variable & & O-HEI-NVSII & HEI-MAC & HEI-EN & HFD Index & ED1 & ED2 \\
\hline \multirow{2}{*}{$\begin{array}{l}\text { Equivalence income } \\
\quad \text { (unit } 1000 € \text { ) }\end{array}$} & $(F)$ & -0.05 & -0.07 & -0.02 & 0.05 & -0.00 & -0.00 \\
\hline & SE & 0.03 & 0.05 & 0.06 & 0.05 & 0.00 & 0.00 \\
\hline \multirow[t]{2}{*}{ Eastern Germany } & $(\mathrm{R})$ & 0.72 & 0.45 & -0.57 & $2 \cdot 45^{\star \star \star}$ & -0.00 & $-0.06^{\star \star}$ \\
\hline & SE & 0.48 & 0.59 & 0.64 & 0.68 & 0.02 & 0.02 \\
\hline \multirow[t]{2}{*}{ Education } & (B) & $0.60^{*}$ & 0.25 & $0.69^{*}$ & $1 \cdot 26^{\star \star \star}$ & 0.00 & -0.01 \\
\hline & SE & 0.24 & 0.31 & 0.32 & 0.37 & 0.01 & 0.01 \\
\hline \multirow[t]{2}{*}{ Job position } & $(\mathrm{F})$ & -0.06 & 0.32 & -0.10 & 0.19 & 0.00 & 0.00 \\
\hline & SE & 0.17 & 0.26 & 0.30 & 0.29 & 0.01 & 0.01 \\
\hline \multirow[t]{2}{*}{ Employed } & $(\mathrm{F})$ & 0.32 & $1 \cdot 28$ & 0.29 & $-1 \cdot 21$ & 0.02 & 0.00 \\
\hline & SE & 0.63 & 1.02 & $1 \cdot 13$ & $1 \cdot 16$ & 0.02 & 0.02 \\
\hline \multirow[t]{2}{*}{ Single } & $(F)$ & -0.26 & -0.43 & $2 \cdot 65^{\star}$ & $-2 \cdot 38^{+}$ & 0.01 & 0.04 \\
\hline & SE & 0.82 & 1.12 & 1.32 & 1.45 & 0.03 & 0.03 \\
\hline \multirow[t]{2}{*}{ Household size } & $(\mathrm{F})$ & $-0 \cdot 15$ & -0.71 & -0.37 & -0.50 & 0.01 & -0.01 \\
\hline & SE & 0.36 & 0.48 & 0.58 & 0.61 & 0.01 & 0.01 \\
\hline \multirow[t]{2}{*}{ Female } & $(\mathrm{R})$ & $2 \cdot 82^{\star \star \star}$ & $2 \cdot 46^{\star \star \star}$ & $1 \cdot 32^{\star}$ & $5 \cdot 34^{\star \star \star}$ & 0.00 & $-0 \cdot 20^{\star \star \star}$ \\
\hline & SE & 0.39 & 0.50 & 0.51 & 0.64 & 0.01 & 0.01 \\
\hline \multirow[t]{2}{*}{ Age } & $(F)$ & -0.12 & 0.06 & 1.25 & $-2 \cdot 70^{\star \star}$ & -0.02 & -0.01 \\
\hline & SE & 0.51 & 0.80 & 0.93 & 0.95 & 0.02 & 0.02 \\
\hline \multirow[t]{2}{*}{ Age squared } & $(\mathrm{F})$ & -0.00 & 0.00 & 0.00 & 0.00 & 0.00 & 0.00 \\
\hline & SE & 0.00 & 0.00 & 0.00 & 0.00 & 0.00 & 0.00 \\
\hline \multirow{2}{*}{ Birth cohort } & (R) & 0.50 & 0.83 & 0.60 & -0.95 & 0.02 & -0.00 \\
\hline & SE & 0.52 & 0.71 & 0.76 & 0.82 & 0.02 & 0.02 \\
\hline \multirow[t]{2}{*}{ Physical exercise } & $(\mathrm{F})$ & 0.01 & 0.02 & 0.02 & 0.05 & 0.00 & -0.00 \\
\hline & SE & 0.02 & 0.03 & 0.03 & 0.04 & 0.02 & 0.00 \\
\hline \multirow[t]{2}{*}{ Weekend } & (B) & -0.18 & -0.52 & 0.17 & -0.51 & 0.01 & -0.01 \\
\hline & $\mathrm{SE}$ & 0.71 & 0.95 & 0.96 & 1.15 & 0.01 & 0.02 \\
\hline \multirow[t]{2}{*}{ Special day } & (B) & -0.57 & 0.47 & $-1.49^{+}$ & -1.09 & -0.01 & $0.05^{\star \star}$ \\
\hline & SE & 0.59 & 0.74 & 0.78 & 0.92 & 0.02 & 0.02 \\
\hline \multirow{2}{*}{ Spring } & (B) & 0.66 & -0.25 & 0.21 & 0.86 & $-0.05^{\star *}$ & 0.01 \\
\hline & SE & 0.64 & 0.86 & 0.89 & 1.09 & 0.02 & 0.02 \\
\hline \multirow[t]{2}{*}{ Summer } & (B) & 0.79 & -0.13 & -0.89 & 1.59 & 0.02 & 0.00 \\
\hline & SE & 0.65 & 0.88 & 0.94 & 1.09 & 0.02 & 0.02 \\
\hline \multirow[t]{2}{*}{ Fall } & (B) & 1.06 & 0.26 & -0.88 & 1.00 & -0.00 & 0.01 \\
\hline & SE & 0.64 & 0.86 & 0.90 & 1.06 & 0.00 & 0.02 \\
\hline \multirow[t]{2}{*}{ NVSII (2005-7) } & $(F)$ & -0.58 & 3.55 & $8 \cdot 19$ & $-11.59^{\star}$ & $-0.17^{+}$ & $-0 \cdot 10$ \\
\hline & SE & 3.01 & 4.65 & $5 \cdot 21$ & $5 \cdot 17$ & 0.10 & 0.11 \\
\hline \multirow{2}{*}{$2008 / 9$} & $(F)$ & -0.36 & 1.54 & $5 \cdot 63^{+}$ & $-4 \cdot 16$ & $-0.14^{*}$ & -0.11 \\
\hline & SE & 1.80 & $2 \cdot 66$ & $3 \cdot 15$ & 3.08 & 0.06 & 0.07 \\
\hline \multirow[t]{2}{*}{$2009 / 10$} & $(F)$ & 0.27 & 1.00 & $5 \cdot 01^{*}$ & $-4 \cdot 23^{+}$ & $-0 \cdot 12^{\star *}$ & $-0.09^{+}$ \\
\hline & SE & 1.30 & 2.00 & $2 \cdot 28$ & $2 \cdot 25$ & 0.04 & 0.05 \\
\hline \multirow[t]{2}{*}{$2010 / 11$} & $(F)$ & 0.10 & 1.45 & 1.25 & -2.55 & $-0.08^{\text {** }}$ & $-0.08^{\star}$ \\
\hline & SE & 0.90 & 1.34 & 1.47 & 1.58 & 0.03 & 0.03 \\
\hline Constant & & $42 \cdot 19^{+}$ & $40 \cdot 41$ & $60 \cdot 61^{+}$ & $95 \cdot 26^{\star \star}$ & 0.82 & $2 \cdot 12^{\star \star}$ \\
\hline & SE & $22 \cdot 12$ & 30.08 & $32 \cdot 02$ & 34.74 & 0.77 & 0.80 \\
\hline$n \times T$ & & 4114 & 4114 & 4114 & 4114 & 4114 & 4114 \\
\hline$n$ & & 2243 & 2243 & 2243 & 2243 & 2243 & 2243 \\
\hline Log pseudolikelihood & & $-14956 \cdot 71$ & -16187.99 & -16547.57 & -16961.52 & $-941 \cdot 29$ & -1223.53 \\
\hline
\end{tabular}

O-HEI-NVSII, Optimised Healthy Eating Index (HEI); HEI-MAC, HEl based on macronutrient (MAC) intake recommendations; HEI-EN, HEI based on overall energy (EN) intake recommendations; HFD, Healthy Food Diversity; ED1, energy density (non-beverages and caloric beverages); ED2, energy density (non-beverages only).

,$+ P<0.10 ;{ }^{*}, P<0.05 ;{ }^{\star *}, P<0.01 ;{ }^{* \star}, P<0.001$

†Unstandardised regression coefficients with standard errors. R stands for random, $\mathrm{F}$ for fixed and B for between effect. All standard errors are clustered by individual and, therefore, robust with respect to heteroscedasticity and autocorrelation. Data source: NEMONIT from Max RubnerInstitute ${ }^{(25)}$.

social causes of healthy diets and its impacts on obesity and SES. We analyse two German socio-epidemiological panel survey datasets (KiGGS and NEMONIT) covering an age range between 0 and 82 years and a time span between 2003 and 2013. We exploit their longitudinal structure utilising hybrid generalised linear mixed panel regression models. Generally, these models have the advantage of being able to cancel out the influence of changes in unobservables affecting both the observed covariates and the outcome. Thus, these models estimate unbiased causal effects (if strict exogeneity is given) ${ }^{(44)}$. In addition, hybrid models allow the inclusion of time-invariant variables.

Altogether, the results for the social causation path (a) indicate that sex, education and age are able to explain healthy diets of German children, adolescents and adults. 
Healthy nutrition in Germany

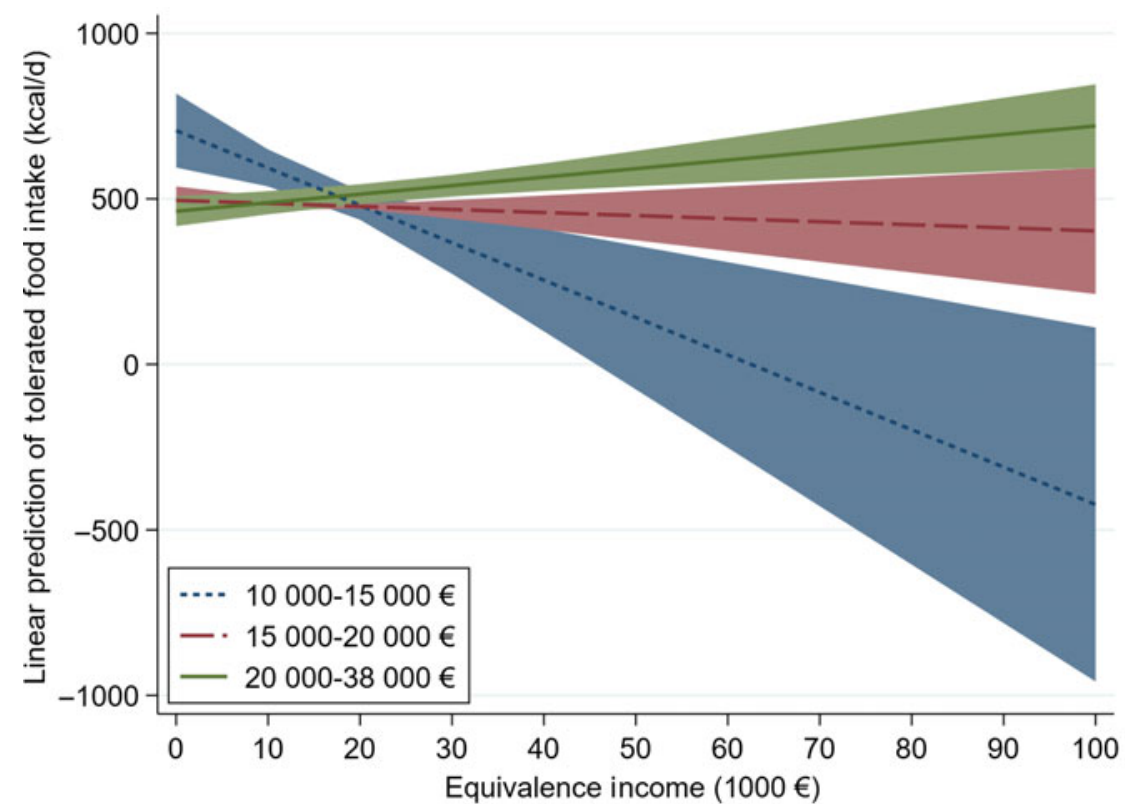

Fig. 2 (colour online) KiGGS: Predictive margins of equivalence income for tolerated food group intake by county-level disposable income (model 4 of Table 3) with $95 \%$ Cl. The figure displays the interaction effect of equivalence income and county-level disposable income on tolerated food intake. Data sources: KiGGS panel from Robert Koch-Institute; country-level disposable income from Regional Database Germany of the statistical offices of the confederation and the federal states

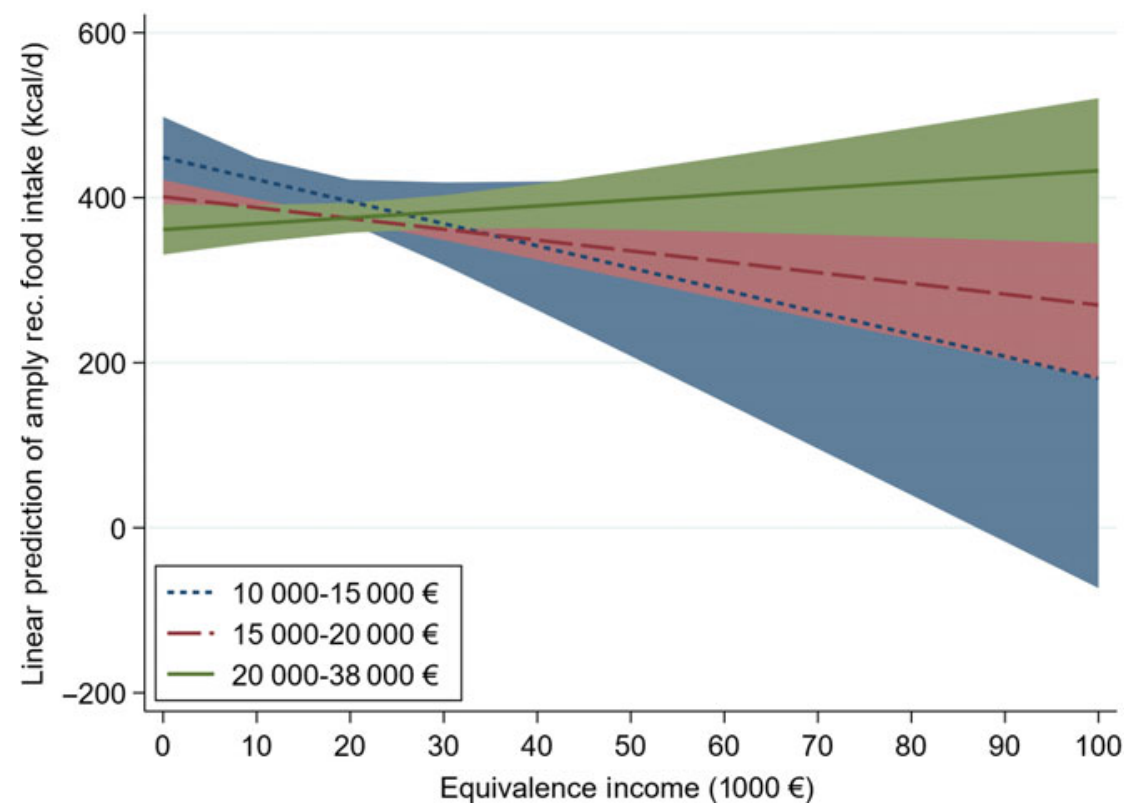

Fig. 3 (colour online) KiGGS: Predictive margins of equivalence income for amply recommended food group intake by county-level disposable income (model 3 of Table 3 ) with $95 \% \mathrm{Cl}$. The figure displays the interaction effect of equivalence income and countylevel disposable income on amply recommended food intake. Data sources: KiGGS panel from Robert Koch-Institute; country-level disposable income from Regional Database Germany of the statistical offices of the confederation and the federal states

Women and people with higher educational attainment/ background eat healthier and have a more diverse diet. However, ageing is associated with losses in dietary variety starting with adulthood. This finding is new, since former cross-sectional studies were only able to detect cohort effects. Our analysis of panel data can control for birth cohort and hence identify a genuine effect of ageing. Furthermore, this disconfirms the assumption that in youth, increasing peer influence and diminishing parental control over the offspring's diet makes it unhealthier and one-sided. This refers to the fact that this conception was based on negative cohort effects spotted in cross-sectional studies ${ }^{(16)}$. 
Table 5 German National Nutrition Monitoring (NEMONIT): generalised mixed-effects regressions of BMI: $1 \dagger$

\begin{tabular}{|c|c|c|c|c|c|c|c|}
\hline Model & & & & 2 & 3 & 4 & 5 \\
\hline Dependent variable & & 1.1 & 1.2 & BMI & BMI & BMI & BMI \\
\hline Intake in & & BMI & BMI & $100 \mathrm{~g} / \mathrm{d}$ & $\% \mathrm{kcal} / \mathrm{d}$ & $100 \mathrm{~g} / \mathrm{d}$ & $100 \mathrm{kcal} / \mathrm{d}$ \\
\hline \multirow[t]{2}{*}{ O-HEI-NVSII } & $(\mathrm{F})$ & $-0.01^{\star *}$ & $-0.01^{\star *}$ & & & & \\
\hline & SE & 0.00 & 0.00 & & & & \\
\hline \multirow[t]{2}{*}{ HFD } & $(\mathrm{F})$ & -0.00 & -0.00 & & & & \\
\hline & SE & 0.00 & 0.00 & & & & \\
\hline \multirow[t]{2}{*}{ ED1 } & $(\mathrm{F})$ & $-0 \cdot 30^{\star \star \star}$ & & & & & \\
\hline & $\mathrm{SE}$ & 0.07 & & & & & \\
\hline \multirow[t]{2}{*}{ ED2 } & $(\mathrm{F})$ & $-0 \cdot 17^{\star}$ & & & & & \\
\hline & SE & 0.07 & & & & & \\
\hline \multirow{2}{*}{ Overall energy intake } & $(F)$ & $0.01^{*}$ & $0.01^{*}$ & & & & \\
\hline & SE & 0.00 & 0.00 & & & & \\
\hline \multirow{2}{*}{ Carbohydrates } & $(\mathrm{F})$ & & & 0.05 & & & \\
\hline & SE & & & 0.04 & & & \\
\hline \multirow[t]{2}{*}{ Fats } & $(F)$ & & & $-0 \cdot 01$ & $-0 \cdot 16$ & & \\
\hline & SE & & & 0.10 & 0.30 & & \\
\hline \multirow[t]{2}{*}{ Proteins } & $(\mathrm{F})$ & & & 0.13 & $0 \cdot 12$ & & \\
\hline & SE & & & 0.12 & 0.60 & & \\
\hline \multirow[t]{2}{*}{ Alcohol (ethanol) } & $(F)$ & & & $0 \cdot 28^{*}$ & $1 \cdot 00^{*}$ & & \\
\hline & SE & & & 0.11 & 0.42 & & \\
\hline \multirow[t]{2}{*}{ Dietary fibre } & $(\mathrm{F})$ & & & $-0 \cdot 29$ & & & \\
\hline & SE & & & 0.32 & & & \\
\hline \multirow{2}{*}{ Amply recommended } & $(\mathrm{F})$ & & & & & 0.00 & 0.01 \\
\hline & SE & & & & & 0.00 & 0.01 \\
\hline \multirow[t]{2}{*}{ Moderately recommended } & $(\mathrm{F})$ & & & & & 0.02 & $0.02^{*}$ \\
\hline & $\mathrm{SE}$ & & & & & 0.01 & 0.01 \\
\hline \multirow[t]{2}{*}{ Sparsely recommended } & $(\mathrm{F})$ & & & & & $-0 \cdot 14$ & -0.02 \\
\hline & SE & & & & & 0.09 & 0.01 \\
\hline \multirow[t]{2}{*}{ Tolerated } & $(F)$ & & & & & $0.02^{\star \star \star}$ & 0.01 \\
\hline & SE & & & & & 0.00 & 0.01 \\
\hline Female & $(\mathrm{R})$ & $-1 \cdot 67^{\star \star \star}$ & $-1 \cdot 71^{\star \star *}$ & $-1 \cdot 65^{\star \star \star}$ & $-1 \cdot 61^{\star \star *}$ & $-1 \cdot 64^{\star \star *}$ & $-1 \cdot 66^{\star \star *}$ \\
\hline & SE & 0.19 & 0.19 & 0.19 & $0 \cdot 16$ & $0 \cdot 18$ & 0.19 \\
\hline Age & $(\mathrm{F})$ & -0.04 & -0.04 & -0.04 & -0.03 & -0.05 & -0.04 \\
\hline & SE & 0.05 & 0.05 & 0.05 & 0.05 & 0.05 & 0.05 \\
\hline Birth cohort & $(\mathrm{R})$ & -0.01 & -0.01 & -0.01 & -0.01 & -0.02 & -0.01 \\
\hline & SE & 0.06 & 0.06 & 0.06 & 0.06 & 0.06 & 0.06 \\
\hline Physical exercise & $(\mathrm{F})$ & $-0.01^{\star * *}$ & $-0 \cdot 01^{\star \star \star}$ & $-0 \cdot 01^{\star \star \star}$ & $-0.01^{\star \star \star}$ & $-0 \cdot 01^{\star \star \star}$ & $-0 \cdot 01^{\star \star \star}$ \\
\hline & SE & 0.00 & 0.00 & 0.00 & 0.00 & 0.00 & 0.00 \\
\hline Weekend & (B) & -0.07 & -0.06 & -0.03 & 0.08 & 0.20 & 0.04 \\
\hline & SE & 0.36 & 0.36 & 0.35 & 0.35 & 0.36 & 0.35 \\
\hline Special day & (B) & 0.03 & 0.05 & 0.29 & 0.35 & 0.05 & $0 \cdot 17$ \\
\hline & SE & 0.29 & 0.29 & 0.29 & 0.29 & 0.29 & 0.29 \\
\hline Spring & (B) & $0.74^{*}$ & $0.75^{\star}$ & 0.51 & 0.53 & $0.63^{+}$ & $0 \cdot 66^{+}$ \\
\hline & SE & 0.36 & 0.36 & 0.35 & 0.35 & 0.36 & 0.36 \\
\hline Summer & (B) & $0.73^{+}$ & $0.73^{+}$ & 0.61 & 0.54 & 0.57 & $0.68^{+}$ \\
\hline & SE & 0.38 & 0.38 & 0.37 & 0.37 & 0.38 & 0.38 \\
\hline Fall & (B) & $0 \cdot 19$ & $0 \cdot 19$ & 0.14 & 0.11 & 0.04 & $0 \cdot 13$ \\
\hline & SE & 0.34 & 0.34 & 0.33 & 0.33 & 0.34 & 0.33 \\
\hline NVSII (2005-7) & $(\mathrm{F})$ & $-0.59^{+}$ & $-0.56^{+}$ & $-0.56^{+}$ & $-0.55^{+}$ & $-0 \cdot 63^{*}$ & $-0.57^{+}$ \\
\hline & SE & 0.31 & 0.31 & 0.31 & 0.31 & 0.31 & 0.31 \\
\hline 2008/9 & $(\mathrm{F})$ & $-0.42^{*}$ & $-0.41^{*}$ & $-0.41^{*}$ & $-0.40^{*}$ & $-0.44^{*}$ & $-0.42^{*}$ \\
\hline & SE & 0.18 & $0 \cdot 18$ & $0 \cdot 18$ & $0 \cdot 19$ & $0 \cdot 18$ & $0 \cdot 18$ \\
\hline $2009 / 10$ & $(\mathrm{~F})$ & $-0 \cdot 30^{*}$ & $-0.29^{*}$ & $-0.29^{*}$ & $-0.27^{*}$ & $-0.32^{*}$ & $-0.29^{*}$ \\
\hline & SE & 0.13 & 0.13 & 0.13 & 0.13 & 0.13 & 0.13 \\
\hline $2010 / 11$ & $(\mathrm{~F})$ & $-0 \cdot 22^{\star *}$ & $-0 \cdot 22^{\star \star}$ & $-0 \cdot 22^{\star *}$ & $-0 \cdot 21^{*}$ & $-0 \cdot 23^{\star \star}$ & $-0 \cdot 22^{\star \star}$ \\
\hline & SE & 0.08 & 0.08 & 0.08 & 0.08 & 0.08 & 0.08 \\
\hline Constant & & $27 \cdot 48^{\star \star \star}$ & $28 \cdot 73^{\star \star \star}$ & $24 \cdot 47^{\star \star \star}$ & $19 \cdot 27^{\star \star \star}$ & $23 \cdot 01^{\star * *}$ & $24 \cdot 48^{\star \star \star}$ \\
\hline & SE & $2 \cdot 84$ & 2.98 & $2 \cdot 78$ & $2 \cdot 83$ & $2 \cdot 77$ & $2 \cdot 78$ \\
\hline$n \times \mathrm{T}$ & & 8446 & 8446 & 8446 & 8446 & 8446 & 8446 \\
\hline$n$ & & 2582 & 2582 & 2582 & 2582 & 2582 & 2582 \\
\hline Log pseudolikelihood & & -17271.55 & $-17279 \cdot 79$ & $-17230 \cdot 17$ & $-17232 \cdot 32$ & $-17267 \cdot 77$ & $-17259 \cdot 64$ \\
\hline
\end{tabular}

O-HEI-NVSII, Optimised Healthy Eating Index (HEI); HFD, Healthy Food Diversity; ED1, energy density (non-beverages + energetic beverages); ED2, energy density (nonbeverages).

,$+ P<0.10 ;{ }^{*}, P<0.05 ;{ }^{\star *}, P<0.01 ;{ }^{* \star}, P<0.001$

fUnstandardised regression coefficients with standard errors. $\mathrm{R}$ stands for random, $\mathrm{F}$ for fixed and $\mathrm{B}$ for between effect. All standard errors are clustered by individual and, therefore, robust with respect to heteroscedasticity and autocorrelation. Data source: NEMONIT from Max Rubner-Institute ${ }^{(25)}$. 
Healthy nutrition in Germany

Table 6 German National Nutrition Monitoring (NEMONIT): generalised mixed-effects regressions of BMI: $2 \dagger$

\begin{tabular}{|c|c|c|c|c|c|}
\hline Model & & 6 & 7 & 8 & 9 \\
\hline Dependent variable & & BMI & BMI & BMI & BMI \\
\hline Intake in & & $100 \mathrm{~g} / \mathrm{d}$ & $100 \mathrm{kcal} / \mathrm{d}$ & $100 \mathrm{~g} / \mathrm{d}$ & $100 \mathrm{kcal} / \mathrm{d}$ \\
\hline \multirow{2}{*}{ Bread, cereals, potatoes, pasta, rice } & $(F)$ & 0.02 & 0.01 & & \\
\hline & SE & 0.02 & 0.01 & & \\
\hline \multirow[t]{2}{*}{ Fruits } & $(F)$ & 0.00 & 0.00 & & \\
\hline & SE & 0.01 & 0.02 & & \\
\hline \multirow{2}{*}{ Vegetables } & $(F)$ & 0.01 & 0.05 & & \\
\hline & SE & 0.02 & 0.04 & & \\
\hline \multirow[t]{2}{*}{ Milk (products) } & $(F)$ & -0.01 & -0.01 & & \\
\hline & SE & 0.01 & 0.01 & & \\
\hline \multirow[t]{2}{*}{ Meat, meat products, fish, eggs } & $(F)$ & $0.07^{\star \star \star}$ & $0.04^{\star \star \star}$ & & \\
\hline & SE & 0.02 & 0.01 & & \\
\hline \multirow[t]{2}{*}{ Edible fats } & $(F)$ & $-0 \cdot 16^{+}$ & -0.02 & & \\
\hline & SE & 0.09 & 0.01 & & \\
\hline \multirow{2}{*}{ Confectionery, snack items } & $(F)$ & 0.00 & -0.00 & & \\
\hline & SE & 0.02 & 0.01 & & \\
\hline \multirow{2}{*}{ Water } & $(F)$ & 0.01 & & & \\
\hline & SE & 0.00 & & & \\
\hline \multirow[t]{2}{*}{ Coffee, tea } & $(F)$ & $-0.01^{+}$ & $-0.67^{+}$ & & \\
\hline & SE & 0.00 & 0.35 & & \\
\hline \multirow[t]{2}{*}{ Juices } & $(F)$ & 0.01 & 0.01 & & \\
\hline & SE & 0.01 & 0.02 & & \\
\hline \multirow[t]{2}{*}{ Sweetened soft drinks } & $(F)$ & $0.03^{\star *}$ & $0 \cdot 13^{* *}$ & & \\
\hline & SE & 0.01 & 0.05 & & \\
\hline \multirow[t]{2}{*}{ Alcoholic beverages } & $(F)$ & $0.02^{\star \star \star}$ & $0.03^{\star}$ & & \\
\hline & SE & 0.01 & 0.01 & & \\
\hline \multirow[t]{2}{*}{ Nuts, seeds } & $(F)$ & & & $-0.26^{*}$ & $-0.05^{\star}$ \\
\hline & SE & & & 0.13 & 0.02 \\
\hline \multirow[t]{2}{*}{ Meat } & $(F)$ & & & $0.07^{*}$ & $0.03^{*}$ \\
\hline & SE & & & 0.03 & 0.01 \\
\hline \multirow[t]{2}{*}{ Meat products } & $(F)$ & & & $0.08^{*}$ & $0.03^{*}$ \\
\hline & SE & & & 0.03 & 0.01 \\
\hline \multirow[t]{2}{*}{ Fish } & $(F)$ & & & -0.02 & -0.01 \\
\hline & SE & & & 0.03 & 0.03 \\
\hline \multirow[t]{2}{*}{ Eggs } & $(F)$ & & & 0.05 & 0.03 \\
\hline & SE & & & 0.07 & 0.04 \\
\hline \multirow[t]{2}{*}{ Lemonade } & $(F)$ & & & $0.04^{\star \star *}$ & $0.19^{\star *}$ \\
\hline & SE & & & 0.01 & 0.06 \\
\hline Beer & $(F)$ & & & $0.02^{\star \star \star}$ & $0.05^{\star \star \star}$ \\
\hline & SE & & & 0.01 & 0.01 \\
\hline (Sparkling) wine & $(F)$ & & & 0.00 & -0.00 \\
\hline & SE & & & 0.01 & 0.02 \\
\hline Spirits & $(F)$ & & & -0.12 & -0.07 \\
\hline & SE & & & $0 \cdot 10$ & 0.06 \\
\hline Female & $(\mathrm{R})$ & $-1 \cdot 27^{\star \star \star}$ & $-1 \cdot 27^{\star \star \star}$ & $-1.06^{\star \star \star}$ & $-1 \cdot 06^{* * \star}$ \\
\hline & SE & 0.19 & 0.20 & 0.20 & 0.20 \\
\hline Age & $(F)$ & -0.05 & -0.04 & -0.05 & -0.04 \\
\hline & SE & 0.05 & 0.05 & 0.05 & 0.05 \\
\hline Birth cohort & $(\mathrm{R})$ & -0.03 & -0.01 & -0.03 & -0.02 \\
\hline & SE & 0.06 & 0.06 & 0.06 & 0.06 \\
\hline Constant & & $22 \cdot 56^{\star \star *}$ & $23 \cdot 81^{\star \star \star}$ & $22 \cdot 25^{\star \star \star}$ & $23 \cdot 76^{\star \star \star}$ \\
\hline & SE & $2 \cdot 73$ & $2 \cdot 74$ & $2 \cdot 73$ & $2 \cdot 74$ \\
\hline$n \times T$ & & 8446 & 8446 & 8446 & 8446 \\
\hline$n$ & & 2582 & 2582 & 2582 & 2582 \\
\hline Log pseudolikelihood & & $-17177 \cdot 84$ & $-17202 \cdot 36$ & $-17130 \cdot 77$ & -17160.93 \\
\hline
\end{tabular}

,$+ P<0.10 ;{ }^{*}, P<0.05 ;{ }^{\star *}, P<0.01 ;{ }^{\star \star \star}, P<0.001$.

†Unstandardised regression coefficients with standard errors. R stands for random, $F$ for fixed and $B$ for between effect. All standard errors are clustered by individual and, therefore, robust with respect to heteroscedasticity and autocorrelation. All models additionally control for physical exercise, observation waves, weekend, special day and the seasons. Models (8) and (9) additionally control for all other food group-specific intake. Data source: NEMONIT from Max Rubner-Institute ${ }^{(25)}$.

For income, we spotted an interaction effect between individual equivalence income and average county-level income on the intake of tolerated foods of children and adolescents. This finding might refer to differential availability structures between amply recommended and tolerated food groups in combination with individual social characteristics that lead to self-selection into rich and poor counties beyond the model at hand. Moreover, we found no direct effect of individual income on dietary quality and variety for both KiGGS and NEMONIT. In sum, these 
Table 7 German National Nutrition Monitoring (NEMONIT): generalised mixed-effects regressions for Germany: socioeconomic status $\dagger$

\begin{tabular}{|c|c|c|c|}
\hline Model & & 1 & 2 \\
\hline Dependent variable & & Equiv. income & Job position \\
\hline \multirow[t]{2}{*}{ Obesity $(\mathrm{BMI} \geq 30)$} & $(F)$ & -0.60 & $-0.22^{*}$ \\
\hline & SE & 0.44 & 0.09 \\
\hline \multirow[t]{2}{*}{ Good health condition } & $(F)$ & 0.06 & $0 \cdot 12^{*}$ \\
\hline & SE & 0.26 & 0.05 \\
\hline \multirow[t]{2}{*}{ Female } & (R) & $-1.52^{\star \star \star}$ & $-0.50^{\star * *}$ \\
\hline & SE & 0.35 & 0.06 \\
\hline \multirow[t]{2}{*}{ Age } & $(F)$ & $0 \cdot 16$ & 0.00 \\
\hline & SE & 0.23 & 0.05 \\
\hline \multirow[t]{2}{*}{ Birth cohort } & (R) & $0.68^{*}$ & 0.05 \\
\hline & SE & 0.29 & 0.06 \\
\hline \multirow[t]{2}{*}{ Weekend } & (B) & 0.63 & -0.04 \\
\hline & SE & 0.75 & 0.12 \\
\hline \multirow[t]{2}{*}{ Special day } & (B) & $2 \cdot 67^{\star \star \star}$ & $0.47^{\text {** }}$ \\
\hline & SE & 0.64 & 0.10 \\
\hline \multirow[t]{2}{*}{ Spring } & (B) & 0.92 & -0.05 \\
\hline & SE & 0.76 & 0.13 \\
\hline \multirow[t]{2}{*}{ Summer } & (B) & 0.45 & -0.14 \\
\hline & SE & 0.75 & $0 \cdot 13$ \\
\hline \multirow{2}{*}{ Fall } & (B) & 0.69 & 0.04 \\
\hline & SE & 0.72 & 0.12 \\
\hline \multirow[t]{2}{*}{ NVSII (2005-7) } & $(\mathrm{F})$ & -1.49 & -0.35 \\
\hline & SE & 1.42 & 0.28 \\
\hline \multirow[t]{2}{*}{$2008 / 9$} & $(\mathrm{~F})$ & $-1 \cdot 80^{*}$ & -0.03 \\
\hline & SE & 0.83 & 0.17 \\
\hline \multirow[t]{2}{*}{$2009 / 10$} & $(F)$ & $-1 \cdot 86^{\star \star}$ & -0.07 \\
\hline & SE & $0 \cdot 61$ & 0.12 \\
\hline \multirow[t]{2}{*}{$2010 / 11$} & $(\mathrm{~F})$ & $-1 \cdot 08^{\star \star}$ & -0.07 \\
\hline & SE & 0.39 & 0.08 \\
\hline \multirow[t]{2}{*}{ Constant } & & $-12 \cdot 89$ & $1 \cdot 37$ \\
\hline & SE & $12 \cdot 15$ & $2 \cdot 34$ \\
\hline$n \times T$ & & 6891 & 6891 \\
\hline$n$ & & 2373 & 2373 \\
\hline Log pseudolikelihood & & $-23016 \cdot 21$ & -11514.90 \\
\hline
\end{tabular}

,$+ P<0.10 ;{ }^{*}, P<0.05 ;{ }^{* *}, P<0.01 ;{ }^{* \star *}, P<0.001$.

†Unstandardised regression coefficients with standard errors. $R$ stands for random $\mathrm{F}$ for fixed and $\mathrm{B}$ for between effect. All standard errors are clustered by individual and, therefore, robust with respect to heteroscedasticity and autocorrelation. The estimation of a model regressing education on obesity status was not possible because there is little within-variation in educational attainment over time. Data source: NEMONIT from Max Rubner-Institute ${ }^{(25)}$.

results indicate that affordability matters for healthy diets in KiGGS depending on contextual income only and not for NEMONIT. This expands former studies and generally conforms to the findings by Zagorsky and Smith ${ }^{(20)}$ who discovered no effect of income on fast-food consumption frequency. Food availability was only possible to approximate in KiGGS due to its relatively high number of subjects and sample points. None of the applied indicators (number of retail firms and firms in the food service industry p.c., factory area of trade and industry p.c.) have a substantial effect on intake in German children and adolescents. Also, moving into a large city with more than 100000 inhabitants is not associated with changes in intake and diet quality, disconfirming the findings of Zagorsky and Smith $^{(20)}$

All other factors included in the models referring to the availability and accessibility of foods are not substantially linked to diets. The effects found in the KiGGS panel analysis differ from the cross-sectional analyses for KiGGS that did find differences between subjects' diets with respect to employment status, migration background and age ${ }^{(16)}$. In sum, the applied triple-A model only had limited predictive power in the German context. Moreover, this study could not include further indicators of affordability (e.g. wealth), availability (e.g. number of food outlets within a distance of $1 \mathrm{~km}$ from residence) and accessibility (e.g. nutritional health knowledge). Hence, future studies may focus on extending the model.

With regard to the biological causation path (b), for the first time, we thoroughly investigated the effects of changing dietary quality on BMI using a national socioepidemiological panel study (NEMONIT). We found that increases in a newly developed Optimised Healthy Eating Index (O-HEI-NVSII), which presumably is less prone to assumptions on individual characteristics, slightly decreases BMI, indicating some predictive validity of O-HEI-NVSII. This also confirms the findings of previous studies ${ }^{(21-23)}$. Moreover, and in accordance with clinical trials ${ }^{(47)}$, growth in nuts intake reduces corpulence, pointing to the health-promoting properties of nuts. Growing lemonade, beer, meat and meat product intakes drive corpulence. The findings on the influence of the intake's average ED are in contradiction to former research with cross-sectional data $^{(40,48)}$ and indicate that, despite its intuitive appeal, the ED hypothesis (more ED translates into more BMI) might be flawed because of a potential misconception of the construct of ED that includes the water content of foods. A high ED does not necessarily mean less volume but also dry food items ${ }^{(40,41)}$. Hence, high overall ED does not necessarily imply low satiation. What is more, there are food items like nuts that have a weight-lowering effect ${ }^{(47)}$, as this study also demonstrates (see Table 6). In all, future research is vital for further validation of this finding.

As a whole, this panel analysis of the biological causation path identifies dietary predictors of corpulence. However, this study is not capable of eliminating the potential confounding influence of (epi)genetic disposition and composition of the gut's microbiome ${ }^{(49-53)}$ and other genetic factors ${ }^{(54)}$. Thus, future research that takes account of these factors is essential for the validation of the findings.

In turn, the analysis of the health selection path (c) suggests that developing obesity leads to losses in SES. This might refer to both decreases in productivity ${ }^{(55)}$ and weight stigma ${ }^{(56)}$ that could explain the association between obesity and SES loss. Future research may delve deeper into analysing this mechanism. Figure 4 summarises the empirical results of our analysis of the nutrition cycle for Germany.

Nevertheless, this analysis has some limitations: First, there is a methodological drawback in the KiGGS panel: the baseline survey used self-administered paper-and-pencil interviews, while in KiGGS 1, all interviews were taken out via telephone. Thus, potential measurement bias cannot be ruled out. However, the KiGGS and NEMONIT analyses substantially lead to the same conclusions. Second, individual 


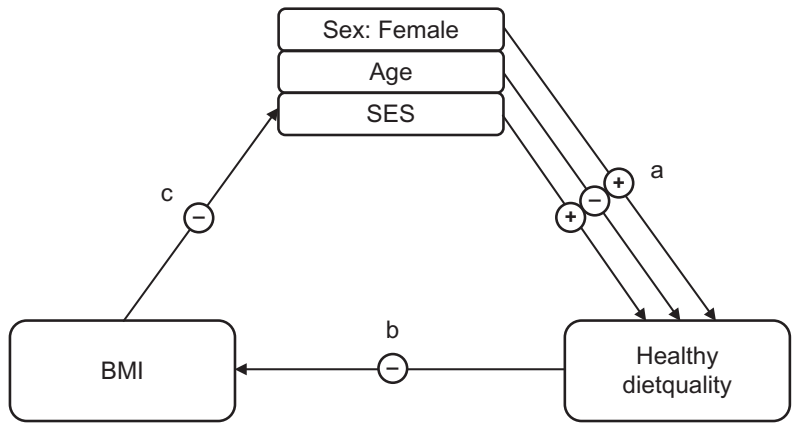

Fig. 4 The nutrition cycle: empirical results for Germany. (a) social causation; (b) biological causation; (c) health selection; + , positive effect; -, negative effect. The results for (a) are based on the panels of the German Health Interview and Examination Survey for Children and Adolescents (KiGGS) and of the German National Nutrition Monitoring (NEMONIT) ${ }^{(25)}$. The results for (b) and (c) are based on NEMONIT only. (a), (b) and (c) apply multiple generalised mixed-effects regressions each

intake is surveyed via self-report. Social desirability and limited ability of retrospection might lead to systematic biases especially concerning the descriptive statistics ${ }^{(57,58)}$. However, Willett ${ }^{(59)}$ concludes that self-reported diet recall for periods of up to 10 years can be reasonably accurate. Third, panel studies are probably subject to selective attrition. It is plausible that over time, the panel drop-out is selective, for example, leading to an overrepresentation of relatively healthy subjects in the panel sample. The fact that individuals' health ratings are relatively stable over time might suggest that this is not much of a problem in NEMONIT. In addition, sample selection only leads to bias if both the covariates and the outcome are correlated with self-selection into the sample ${ }^{(60)}$. Fourth, the accuracy of $\mathrm{BMI}$ in diagnosing obesity in terms of body fat per cent is limited. Hence, future panel studies might utilise more valid - yet more costly - measurements of body fat per cent like bioelectrical impedance analysis ${ }^{(61)}$. Fifth, the analysis is limited to a time span of about a decade covering only a small part of individuals' life spans. With socio-epidemiological panels getting longer, future studies will also be able to analyse the nutritional effects on mortality.

On balance, this study suggests that health-promoting policies targeted at the reduction of obesity prevalence may be well advised to focus on boys and men, people with low educational attainment level and background, as well as on the promotion of a healthy diet including nuts intake, and the limitation of lemonade, beer, meat and meat product intakes. The WHO and the Organisation for Economic Co-operation and Development also urge the latter. Both the WHO and Organisation for Economic Co-operation and Development recommend a stricter regulation for advertising unhealthy foods ${ }^{(1,62)}$, and the WHO favours the implementation of a special tax of at least $20 \%$ on sweetened beverages ${ }^{(63,64)}$. Moreover, the obesitypreventing effect of high levels of education suggests that the establishment of nutritional health equity would probably gain from the further development of settingbased health promotion. Especially advancing communal feeding at educational establishments, from day-care centres to schools, and in office canteens is promising to this end ${ }^{(64,65)}$. Here, imposing mandatory catering standards could be effective ${ }^{(64)}$. Furthermore, the design of decision architecture (i.e. 'nudging') is promising, as it is supposed to be more effective than traditional means of prevention $^{(66-68)}$. Nudging measures like the prominent placing of healthy food items in canteens and grocery stores generally do not involve a social gradient in effectivity, as, for example, it is the case with a traffic light-like labelling of foods ${ }^{(65,68-70)}$. Thus, nudging people into healthy diets may guarantee the primary aims of health promotion - individual autonomy of action and equality of opportunity. However, the challenge remains not only to make the healthy choices the easy choices but also to make them the preferred ones ${ }^{(65)}$. A promising avenue to attain this goal could be the placing of positive incentives via the implementation of consumer rewards for the purchase of healthy food items, for example, as part of loyalty cards of big grocery retailers ${ }^{(71)}$.

\section{Conclusions}

For the first time, this study gains a comprehensive causal insight into the nutrition cycle by identifying the social causes of healthy diets and its impacts on health and wealth in Germany. In all, the results indicate that girls and women, and people with high educational attainment level and background, are less corpulent than boys and men and people with low education. Healthy diets, including nuts intake, promote the reduction of obesity prevalence, while the intake of lemonade, beer, meat and meat products counteracts it. All told, this study advises further research to validate the findings and derive sound recommendations for political action using rigorous panel regression models and more accurate panel data. Many other longitudinal panel studies, especially in Europe and the United States, are still waiting for their longitudinal potentials to be exploited and made fruitful for causal inference.

\section{Acknowledgements}

Acknowledgements: S.M. thanks Prof Dr Axel Franzen (Institute of Sociology, University of Bern), Dr Gert Mensink (Robert Koch-Institute Berlin) and two anonymous referees for helpful comments and suggestions, and the Max Rubner-Institute and Dr Gert Mensink for making the datasets available and accessible for analysis. Financial support: This study was funded by the Bavarian State Ministry for Nutrition, Agriculture, and Forestry (StMELF) within the project 'Nutrition in Bavaria and Its Costs' ('Ernährungsverhalten in Bayern und seine Folgekosten', project number A/15/32) of the Competence Centre of Nutrition (KErn) at the Bavarian State Research 
Center for Agriculture. NVS II and NEMONIT were funded by the German Federal Ministry of Food, Agriculture and Consumer Protection. Conflict of interest: None. Authorship: S.M. developed the concept of the article, analysed the data and wrote a first draft of the manuscript. M.R., W.S. and C.R. also co-developed the concept of the article and revised the manuscript. I.F. and E.-M.T. also revised the manuscript. Ethics of buman subject participation: Not applicable.

\section{Supplementary material}

For supplementary material accompanying this article visit https://doi.org/10.1017/\$1368980019004877

\section{References}

1. OECD (2019) The Heavy Burden of Obesity: The Economics of Prevention. OECD Health Policy Studies. Paris: OECD Publishing.

2. The Global BMI Mortality Collaboration (2016) Body-mass index and all-cause mortality: individual-participant-data meta-analysis of 239 prospective studies in four continents. Lancet 388, 776-786.

3. Kivimäki M, Kuosma E, Ferrie JE et al. (2017) Overweight, obesity, and risk of cardiometabolic multimorbidity: pooled analysis of individual-level data for 120813 adults from 16 cohort studies from the USA and Europe. Lancet Public Health 2, e277-e285.

4. Beyer F, Kharabian Masouleh S, Huntenburg JM et al. (2017) Higher body mass index is associated with reduced default mode connectivity in older adults. Hum Brain Mapp 38, 3502-3515.

5. Schwingshackl L, Schwedhelm C, Galbete C et al. (2017) Adherence to Mediterranean diet and risk of cancer: an updated systematic review and meta-analysis. Nutrients 9, 1063.

6. Zheng J, Guinter MA, Merchant AT et al. (2017) Dietary patterns and risk of pancreatic cancer: a systematic review. Nutr $\operatorname{Rev}$ 75, 883-908.

7. GBD 2015 Risk Factors Collaborators (2016) Global, regional, and national comparative risk assessment of 79 behavioural, environmental and occupational, and metabolic risks or clusters of risks, 1990-2015: a systematic analysis for the Global Burden of Disease Study 2015. Lancet 388, 1659-1724.

8. Konnopka A, Dobroschke A, Lehnert T et al. (2018) The costs of overweight and obesity: a systematic review. Gesundheitswesen 80, 471-481.

9. Schwingshackl L, Bogensberger B \& Hoffmann G (2018) Diet quality as assessed by the Healthy Eating Index, Alternate Healthy Eating Index, Dietary Approaches to Stop Hypertension Score, and health outcomes: an updated systematic review and meta-analysis of cohort studies. J Acad Nutr Diet 118, 74-100.

10. Cawley J \& Ruhm CJ (2012) The economics of risky health behaviors. In Handbook of Health Economics, pp. 95-199 [M Pauly, T McGuire \& PP Barros, editors]. Oxford: North Holland.

11. Muff C (2009) Soziale Ungleichbeiten im Ernährungsverhalten. Theoretische Hintergründe und empirische Befunde (Social Inequalities in Nutritional Behaviour. Theoretical Background and Empirical Findings). Berlin/Wien: LIT Verlag.

12. Kröger H, Pakpahan E \& Hoffmann R (2015) What causes health inequality? A systematic review on the relative importance of social causation and health selection. Eur J Public Health 25, 951-960.
13. Fekete C \& Weyers S (2016) Social inequalities in nutrition. Evidence, causes and interventions. Bundesgesundheitsblatt 59, 197-205.

14. Reisch L \& Gwozdz W (2011) Von der „Macht der Defaults” und vom „Sanften Stupsen”: Verhaltensökonomische Erkenntnisse als Impulse für eine effektive Ernährungspolitik (On the "Power of Defaults" and on "Gentle Nudging": behavioural economic findings as impulses for an effective nutrition policy). In Die Zukunft auf dem Tisch. Analysen, Trends und Perspektiven der Ernäbrung von morgen (The Future on the Table. Analyses, Trends and Perspectives of Tomorrow's Nutrition), pp. 323-336 [G Hirschfelder, A Ploeger \& G Schönberger, editors]. Wiesbaden: VS Verlag für Sozialwissenschaften.

15. Story M, Neumark-Sztainer D \& French S (2002) Individual and environmental influences on adolescent eating behaviors. J Am Diet Assoc 102, 40-51.

16. Mader S, Rubach M \& Schaecke W (2017) The impact of social factors on the nutrition of German children and adolescents. Ernabrungs Umschau 64, 96-100.

17. Mertens E, Clarys P, Mullie P et al. (2017) Stability of physical activity, fitness components and diet quality indices. Eur $J$ Clin Nutr 71, 519-524.

18. Solbak NM, Xu J-Y, Ven JE et al. (2017) Diet quality is associated with reduced incidence of cancer and self-reported chronic disease: observations from Alberta's tomorrow project. Prev Med 101, 178-187.

19. Rummo PE, Guilkey DK, Ng SW et al. (2017) Understanding bias in relationships between the food environment and diet quality: the Coronary Artery Risk Development in Young Adults (CARDIA) study. J Epidemiol Commun Health 71, 1185-1190.

20. Zagorsky JL \& Smith PK (2017) The association between socioeconomic status and adult fast-food consumption in the U.S. Econ Hum Biol 27, 12-25.

21. Mertens E, Deforche B, Mullie P et al. (2015) Longitudinal study on the association between three dietary indices, anthropometric parameters and blood lipids. Nutr Metab 12, 47.

22. Fung TT, Pan A, Hou T et al. (2015) Long-term change in diet quality is associated with body weight change in men and women. J Nutr 145, 1850-1856.

23. Cespedes Feliciano EM, Tinker L, Manson JAE et al. (2016) Change in dietary patterns and change in waist circumference and DXA trunk fat among postmenopausal women. Obesity 24, 2176-2184.

24. Michaud P-C \& van Soest A (2008) Health and wealth of elderly couples: causality tests using dynamic panel data models. J Health Econ 27, 1312-1325.

25. Max Rubner-Institute (2016) Dataset of the German National Nutrition Monitoring (NEMONIT). Karlsruhe, Germany: Max Rubner-Institute.

26. Truthmann J, Mensink GBM \& Richter A (2011) Relative validation of the KiGGS Food Frequency Questionnaire among adolescents in Germany. Nutr J 10, 133.

27. Mauz E, Gösswald A, Kamtsiuris P et al. (2017) New data for action. Data collection for KiGGS Wave 2 has been completed. J Health Monit 2, 2-27.

28. Gose M, Krems C, Heuer T et al. (2016) Trends in food consumption and nutrient intake in Germany between 2006 and 2012: results of the German National Nutrition Monitoring (NEMONIT). Brit J Nutr 115, 1498-1507.

29. HafenCity University Hamburg, University Regensburg (2013) Qualifizierte Nahversorgung im Lebensmitteleinzel handel (Qualified local supply in food retailing). https:// www.hcu-hamburg.de/fileadmin/documents/Professoren_ und_Mitarbeiter/Projektentwicklung_-management/Forschung/ Qualifizierte_Nahversorgung_HCU-IREBS_Endbericht_Lang fassung_Maerz_2013.pdf (accessed December 2018).

30. Mensink GB \& Burger M (2004) Was isst du? Ein Verzehrshäufigkeitsfragebogen für Kinder und Jugendliche 
(What do you eat? A food frequency questionnaire for children and adolescents). Bundesgesundheitsblatt 47, 219-226.

31. Kleiser C, Mensink GBM, Scheidt-Nave C et al. (2009) HuSKY: a healthy nutrition score based on food intake of children and adolescents in Germany. Br J Nutr 102, 610-618.

32. Alexy U, Clausen K \& Kersting M (2008) Die Ernährung gesunder Kinder und Jugendlicher nach dem Konzept der Optimierten Mischkost (The nutrition of healthy children and adolescents according to the concept of Optimized Mixed Diet). Ernabrungs Umschau 3, 168-177.

33. Kersting M, Alexy U \& Clausen K (2005) Using the concept of food based dietary guidelines to develop an Optimized Mixed Diet (OMD) for German children and adolescents. J Pediatr Gastr Nutr 40, 301-308.

34. Drescher LS, Thiele S \& Mensink GBM (2007) A new index to measure healthy food diversity better reflects a healthy diet than traditional measures. J Nutr 137, 647-651.

35. Slimani N, Deharveng G, Charrondiere RU et al. (1999) Structure of the standardized computerized 24-h diet recall interview used as reference method in the 22 centers participating in the EPIC project. European Prospective Investigation into Cancer and Nutrition. Comput Meth Prog Bio 58, 251-266.

36. Oberritter H, Schäbethal K, von Ruesten A et al. (2013) The DGE-nutrition circle - presentation and basis of the food-related recommendations from the German Nutrition Society (DGE). Ernahrungs Umschau 60, 24-29.

37. Gedrich K \& Karg G (2001) Welche Ernährung wäre für die Bevölkerung optimal (Which diet would be optimal for the population)? In Ernährungsziele unserer Gesellschaft: die Beiträge der Ernährungsverhaltenswissenschaft. 22. Wissenschaftliche Jahrestagung der Arbeitsgemeinschaft Ernährungsverhalten e. V. (Nutritional Goals of Our Society: The Contributions of Nutritional Behaviour Science. 22nd Scientific Annual Conference of the Working Group Nutritional Behaviour), pp. 19-38 [U Oltersdorf \& K Gedrich, editors]. Karlsruhe: Bundesforschungsanstalt für Ernährung.

38. DGE - German Nutrition Society, Austrian Nutrition Society \& Swiss Society for Nutrition Research (2013) Referenzwerte für die Nährstoffzufubr (Reference Values for Nutrient Intake). Frankfurt: Umschau-Verlag.

39. DGE - German Nutrition Society (2015) New reference values for energy intake. Ann Nutr Metab 66, 219-223.

40. Drewnowski A, Almiron-Roig E, Marmonier C et al. (2004) Dietary energy density and body weight: is there a relationship? Nutr Rev 62, 403-413.

41. Shrapnel B (2010) Is energy density a useful concept for understanding and preventing obesity? Nutr Diet 67, 281-286.

42. Brüderl J \& Ludwig V (2015) Fixed-effects panel regression. In The SAGE Handbook of Regression Analysis and Causal Inference, pp. 327-358 [H Best \& C Wolf, editors]. London: SAGE.

43. Wooldridge J (2010) Econometric Analysis of Cross-Section and Panel Data. Cambridge: MIT Press.

44. Vaisey S \& Miles A (2017) What you can - and can't - do with three-wave panel data. Social Method Res 46, 44-67.

45. Allison PD (2009) Fixed Effects Regression Models. Thousand Oaks, CA: Sage.

46. Schunck R \& Perales F (2017) Within- and between-cluster effects in generalized linear mixed models: a discussion of approaches and the xthybrid command. Stata J 17, 89-115.

47. Ros E (2010) Health benefits of nuts consumption. Nutrients 2, 652-682.

48. Karl JP \& Roberts SB (2014) Energy density, energy intake, and body weight regulation in adults. Adv Nutr 5, 835-850.

49. Ley RE, Turnbaugh PJ, Klein S et al. (2006) Human gut microbes associated with obesity. Nature 444, 1022-1023.
50. Menni C, Jackson MA, Pallister T et al. (2017) Gut microbiome diversity and high-fibre intake are related to lower long-term weight gain. Int J Obesity 41, 1099-1105.

51. Ott B, Skurk T, Hastreiter L et al. (2017) Effect of caloric restriction on gut permeability, inflammation markers, and fecal microbiota in obese women. Sci Rep 7, 11955.

52. Selber-Hnatiw S, Rukundo B, Ahmadi M et al. (2017) Human gut microbiota: toward an ecology of disease. Front Microbiol 8, 1265.

53. Sommer F, Moltzau Anderson J, Bharti R et al. (2017) The resilience of the intestinal microbiota influences health and disease. Nat Rev Microbiol 15, 630-638.

54. Cohen-Cline H, Lau R, Moudon AV et al. (2015) Associations between fast-food consumption and body mass index: a cross-sectional study in adult twins. Twin Res Hum Genet 18, 375-382.

55. Goettler A, Grosse A \& Sonntag D (2017) Productivity loss due to overweight and obesity: a systematic review of indirect costs. BMJ Open 7, e014632.

56. Brewis AA (2014) Stigma and the perpetuation of obesity. Soc Sci Med 118, 152-158.

57. Hill RJ \& Davies PSW (2001) The validity of self-reported energy intake as determined using the doubly labelled water method. Br J Nutr 85, 415-430.

58. Westerterp KR \& Goris AH (2002) Validity of the assessment of dietary intake: problems of misreporting. Curr Opin Clin Nutr 5, 489-493.

59. Willett W (2013) Nutritional Epidemiology. New York: Oxford University Press.

60. Elwert F \& Winship C (2014) Endogenous selection bias: the problem of conditioning on a collider variable. Annu Rev Sociol 40, 31-53.

61. Romero-Corral A, Somers VK, Sierra-Johnson J et al. (2008) Accuracy of body mass index in diagnosing obesity in the adult general population. Int J Obesity 32, 959-966.

62. World Health Organization (WHO) (2014) European Food and Nutrition Action Plan 2015-2020. Regional Committee for Europe, EUR/RC64/14. Copenhagen: WHO.

63. Spiller A, Zühlsdorf A \& Nitzko S (2017) Instruments of nutrition policy. A research overview - Part 1. Ernabrungs Umschau 64, M146-M153.

64. Spiller A, Zühlsdorf A \& Nitzko S (2017) Instruments of nutrition policy. A research overview - Part 2. Ernabrungs Umschau 64, M204-M210.

65. Hawkes C, Smith TG, Jewell J et al. (2015) Smart food policies for obesity prevention. Lancet 385, 2410-2421.

66. Kenning P \& Reisch L (2013) Alternativen zum Informationsparadigma der Verbraucherpolitik. 1. Verbraucherforum an der Zeppelin Universität, Friedrichshafen, 24. January 2013 (Alternatives to the information paradigm of consumer policy. 1st Consumer Forum at the Zeppelin University Friedrichshafen, 24 January 2013). J Verbrauch Lebensm 8, 227-253.

67. Thaler RH \& Sunstein CR (2009) Nudge. Improving Decisions about Health, Wealth and Happiness. London: Penguin Books.

68. Thorgeirsson T \& Kawachi I (2013) Behavioral economics. Merging psychology and economics for lifestyle interventions. Am J Prev Med 44, 185-189.

69. Kelly B, Hughes C, Chapman K et al. (2009) Consumer testing of the acceptability and effectiveness of front-of-pack food labeling systems for the Australian grocery market. Health Promot Int 24, 120-129.

70. Glanz K, Bader MDM \& Iyer S (2012) Retail grocery store marketing strategies and obesity. An integrative review. Am J Prev Med 42, 503-512.

71. Willett W, Rockström J, Loken B et al. (2019) Food in the Anthropocene: the EAT-Lancet Commission on healthy diets from sustainable food systems. Lancet 393, 447-492. 